Eur Addict Res 1995;1:186

\title{
Announcement
}

\section{European Addiction Research Award}

Outstanding achievements in European addiction research will be rewarded with the 'European Addiction Research Award'. The award has been created for European researchers or research groups from all domains of addiction research who have excelled in innovation, multidisciplinary integration, relevance to Europe and European cooperation. The nominations will be made by an international committee chaired by Prof. Dr. Dr. Ambros Uchtenhagen based on proposals by researchers or institutions.

There will be a special ceremony during the annual congress. For further details please contact: Prof. Dr. Dr. Ambros Uchtenhagen Universität Zurich Sozialpsychiatrischer Dienst Postfach 904 CH-8021 Zurich (Switzerland) Telefax: 004112419443 